\title{
Bidirectional transmission properties of venetian blinds: experimental assessment compared to ray-tracing calculations
}

\author{
M. Andersen ${ }^{\mathrm{a}, *}$, M. Rubin ${ }^{\mathrm{b}}$, R. Powles ${ }^{\mathrm{b}}$, J.-L. Scartezzini ${ }^{\mathrm{a}}$ \\ a Swiss Federal Institute of Technology (EPFL), Solar Energy and Building Physics \\ Laboratory (LESO-PB), Building LE, 1015 Lausanne, Switzerland \\ ${ }^{\mathrm{b}}$ Lawrence Berkeley National Laboratory (LBNL), University of California, 1 \\ Cyclotron Road, MS 2-300, Berkeley CA 94720-8134, USA
}

\begin{abstract}
An accurate evaluation of daylight distribution through advanced fenestration systems (complex glazing, solar shading systems) requires the knowledge of their Bidirectional light Transmission Distribution Function $(B T D F)$. An innovative equipment for the experimental assessment of these bi-directional functions has been developed, based on a digital imaging detection system. An extensive set of BTDF measurements was performed with this goniophotometer on venetian blinds presenting curved slats with a mirror coating on the upper side.

In this paper, the measured data are compared with ray-tracing results achieved with a virtual copy of the device, that was constructed with a commercial raytracing software. The model of the blind was created by implementing the measured reflection properties of the slats coatings in the ray-tracing calculations. These comparisons represent an original and objective validation methodology for detailed bidirectional properties for a complex system; the good agreement between the two
\end{abstract}


methods, yet presenting very different parameters and assessment methodologies, places reliance both on the digital-imaging detection system and calibration, and on the potentiality of a flexible calculation method combining ray-tracing simulations with simple components measurements.

Key words: Bi-directional Transmission Distribution Function (BTDF), Goniophotometer, Solar blinds, Simulation model, Ray-tracing calculations, Daylighting, Solar protection systems

\section{Introduction}

To optimize the use and design of advanced fenestration systems, and thus efficiently control solar gain and daylighting through windows, there is a need for detailed knowledge of their optical properties. As their variation with the angle of incidence often proves to be critical, such properties should be assessed taking both the incident and emerging directions into account, i.e. according to bidirectional measurements (BTDFs, BRDFs), that are performed with a goniophotometer.

As shown by the work presented in M. Andersen et al. (2003), the validation of these data lacks absolute standards on full-scale systems, and ray-tracing calculations thus provide a useful and objective point of comparison for validating BT(R)DF data in a roundabout approach. Furthermore, computational meth-

* Corresponding author: M. Andersen is now at the Massachusetts Institute of Technology (MIT), Building Technology Program, Department of Architecture, Room 5-418, 77 Massachusetts Avenue, Cambridge MA 02139, USA. Tel: +1-617-253-1639; fax: +1-617-253-6152.

Email address: mand@mit.edu (M. Andersen). URL: http://architecture.mit.edu/people/profiles/prander.html (M. Andersen). 
ods prove to be a valuable tool for parametric studies, and their combination with experimental methods, restricting the latter to the optical properties assessment of unknown coatings or materials only, will greatly increase flexibility and efficiency.

Comparisons between different assessment methods for the optical performances of glazing or shading systems have been realized in various ways, such as: to test a new ray-tracing approach for thermal radiation assessment (N.S. Campbell, 1998) or prismatic panels performances (R. Compagnon, 1994); to determine the daylight distribution inside a room and compare RADIANCE calculations with test office measurements (C.F. Reinhart and O. Walkenhorst, 2001); for developing an angle-dependent Solar Heat Gain Coefficient evaluation procedure and comparing measurements either to ray-tracing results obtained with the software OptiCAD ${ }^{\circledR}$ (T.E. Kuhn et al., 2001) or to matrix layer calculations (J.H. Klems et al., 1997); to compare goniophotometric data with results provided by an analytic model (J. Breitenbach et al., 2001; J.L.J. Rosenfeld, 1996).

However, the quantity considered for these comparative studies remained the directional-hemispherical transmittance, which represents the global light transmittance, and as such integrates the associated bidirectional function over the emerging space. After the comparative study made by P. Apian-Bennewitz (1995) on polymers and aerogels, M. Andersen et al. (2003) thus appears as the first extensive comparison of detailed experimental BTDF data with raytracing calculations for an advanced glazing system, namely prismatic panels. This paper goes further in this prospect, by choosing a venetian blind as study case, and consequently increasing the model complexity, as it presents geometric and coating properties less easily modeled than an acrylic prism 
with macroscopic grating. Similar comparisons had actually been attempted before for a venetian blind (R. McCluney and J. Sung, 1999), bidirectional measurements made at LBNL (K.M. Papamichael et al., 1988) being then assessed against ray-tracing calculations performed with the commercial software $\operatorname{AsAP}^{\circledR 1}$. Unfortunately, the results did not concur, the discrepancies remaining too significant to allow any conclusion regarding the method's accuracy, even from a qualitative point of view.

Experimental conditions for $B T D F$ characterization were here reproduced virtually with the commercial forward ray-tracer TRACEPRO ${ }^{\circledR 2}$ for a venetian blind prototype manufactured by Baumann-Hüppe AG. This blind presents curved slats with a mirror coating on the upper side, whose reflective properties were determined experimentally and implemented in the model. Computer simulation results were then compared to measured BTDF data, that were assessed with the digital imaging-based goniophotometer developed at the Swiss Federal Institute of Technology (EPFL) (M. Andersen et al., 2001; M. Andersen, 2002).

\section{Characteristics and modeling of venetian blinds}

The venetian blind considered in this study is shown on Figure 1. As detailed in section 2.2 , the mirror coating makes the concave upper slat side a very specular surface, whereas the stone grey paint presents quasi-lambertian diffuse properties (see section 2.2). These features increase the interest of analyzing such a system, as the numerous inter-reflections undergone by the incident

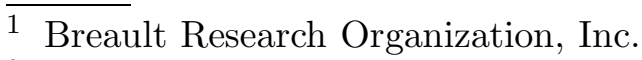

2 TracePro ${ }^{\circledR}$, v. 2.3 \& 2.4, Lambda Research Corporation. 
light rays consist of a combination of very different reflection types.

Before modeling a system with a ray-tracing tool, its geometric and coating characteristics have to be precisely and fully known, in order to be implemented properly in the model.

\subsection{Geometric properties}

The slat's geometric properties were determined with micrometric measurement tools. The obtained dimensions are given in Figure 2; the radius of curvature $R_{\text {slat }}$, deduced from the slat's thickness $\xi$, width $l_{\text {slat }}$ and curvature amplitude $e_{\text {slat }}$, was found equal to $96.9 \mathrm{~mm}$.

Through a combination of subtractions and intersections of primitive solids (Fig. 3(a)), a virtual element presenting the same features was created in TrACEPro ${ }^{\circledR}$, and its edges were thereafter rounded to avoid aberrant ray paths.

An arrangement of 7 of these individual slats was then created according to the measured positions of the physical ones on the sample holder; as far as the modeling of the $45^{\circ}$ tilt configuration is concerned, the slats' rotation axes were defined taking the dimensions of the mechanical revolving system into account. The obtained venetian blind model is represented on Figure 3(b) for this configuration. 


\subsection{Mirror and paint coatings}

The assessment of the reflective properties of the slats' paint and mirror coatings was achieved at LBNL using the Perkin-Elmer Lambda 19 spectrophotometer with an integrating sphere accessory. The reflectance was measured for normal incidence every $5 \mathrm{~nm}$ between 300 and $2500 \mathrm{~nm}$ on both sides, and the obtained spectra were corrected with the known reflectance of a calibrated diffuse reflectance standard made of Spectralon. Photopic averages were then taken using the D65 source and CIE 1931 2-degrees observer functions (CIE, 1932); the resulting visible (photopic) total reflectances were $28.6 \%$ and $83.7 \%$ for the paint and mirror surfaces respectively.

The obtained spectra are shown on Figure 4 over the complete wavelength interval; their approximation with $50 \mathrm{~nm}$ wavelength steps was used for implementing the spectral reflective properties of the coatings into the ray-tracing tool.

For both coatings, the reflectance was measured with and without a light trap to collect the specularly reflected beam. For the paint surface, the scans were almost identical, which means that the reflectance is very diffuse; for the mirror, the scan with light trap was almost zero at all visible wavelengths, showing that it presents highly specular properties. In addition to that, the paint surface value was checked with a different apparatus (Colorimeter CR-200b Minolta for assessing the color coordinates and reflectance of diffuse surfaces) and the results were found to be very close (difference of $3 \%$ ). When creating the coatings files for $\operatorname{TRACEPRO}^{\circledR}$, only a slight $(\sim 2 \%)$ relative specular component was thus added over the whole spectrum for the paint surface, and 
likewise a scattering component for the mirror, otherwise considered respectively perfectly lambertian and specular.

\section{Virtual goniophotometer copy}

The experimental assessment method is described in M. Andersen et al. (2001) and illustrated by Figure 5(a): instead of being scanned by moving a sensor from point to point, the light flux emerging from the investigated sample is collected by a diffusing flat screen, at which a calibrated Charge-Coupled Device (CCD) camera is aiming, used as a multiple-points luminance-meter. To cover all possible emerging directions ( $2 \pi$ steradian), the camera and the screen perform rotations of a $60^{\circ}$ angle magnitude, leading to the visualization of the whole transmitted hemisphere in a continuous way within a few minutes. The assessment method of the bidirectional goniophotometer differs from conventional ones in the way that it splits the emerging hemisphere into a regular grid of averaging sectors, illustrated in Figure 5(b), thus preventing from any risk of missing a discontinuity in the emerging luminance figure; the produced set of BTDF data in consequence truly represents adjacent hemisphere portions, each corresponding to a particular combination of incident and transmitted directions. The spherical coordinate system used to describe $B T D F \mathrm{~s}$ is illustrated in Figure 6: its origin is placed on the characterized component itself and the directions are defined by their respective altitude and azimuth angles: $\theta_{i}$ is comprised between $0^{\circ}$ and $90^{\circ}$ and $\phi_{i}$ is comprised between $0^{\circ}$ and $360^{\circ}$, where index $\mathrm{i}$ indicates whether the angle is related to the incident $(\mathrm{i}=1)$ or transmitted $(\mathrm{i}=2)$ direction.

To reproduce these assessment conditions virtually, a copy of the goniopho- 
tometer was modeled, of same characteristics as the one presented in M. Andersen et al. (2003) (virtual light source as a set of wavelengths weighted according to the physical source's spectrum and of appropriate spread angle, detection system as an arrangement of six triangular screens split along regular azimuth and altitude angles), except for the following features:

- the angular grid for BTDF averaging here corresponded to $\Delta \theta_{2}$ and $\Delta \phi_{2}$ intervals equal to $10^{\circ}$ and $15^{\circ}$ respectively, in order to fit the one adopted for the measurements; the detection screens models have thus been altered accordingly, as illustrated in Figure 7(a)

- the sample diaphragm diameter was set to $15 \mathrm{~cm}$, also to be coherent with the actual measurement conditions

- as the rays undergo diffuse reflectances, the flux threshold (fractional value of starting flux for which a ray will be terminated) was lowered to $0.1 \%$ in order to keep sufficient track of the scattered rays for a reliable $B T D F$ estimation.

The venetian blind's BTDF was determined experimentally for a set of 23 different incident directions for two slats arrangements, horizontal ( $0^{\circ}$ tilt) and oblique ( $45^{\circ}$ tilt), amongst which 10 were selected for comparisons to simulations for the $0^{\circ}$ slats and 5 for the $45^{\circ}$ slats: for the $0^{\circ}$ slats tilt configuration, these incident directions were $\left(0^{\circ}, 0^{\circ}\right),\left(12^{\circ}, 90^{\circ}\right),\left(60^{\circ}, 90^{\circ}\right),\left(20^{\circ}, 270^{\circ}\right)$, $\left(40^{\circ}, 270^{\circ}\right),\left(53^{\circ}, 1^{\circ}\right),\left(31^{\circ}, 30^{\circ}\right),\left(17^{\circ}, 45^{\circ}\right),\left(68^{\circ}, 45^{\circ}\right)$ and $\left(72^{\circ}, 61^{\circ}\right)$, the last five being based on realistic sun positions for a South-oriented window at latitude $47^{\circ} \mathrm{N}$; for the $45^{\circ}$ slats tilt, the incident directions were $\left(0^{\circ}, 0^{\circ}\right),\left(12^{\circ}, 90^{\circ}\right)$, $\left(20^{\circ}, 270^{\circ}\right),\left(17^{\circ}, 45^{\circ}\right)$ and $\left(50^{\circ}, 315^{\circ}\right)$ (same for the last two).

The considered quantitative output in simulation is the total photometric 
flux collected by each angular sector on the projection screens, summed up according to $V(\lambda)$ for all traced wavelengths. Dividing each of these individual fluxes by the incident flux to get the normalized fluxes $\Phi_{2_{\text {norm }}}\left(\theta_{2}, \phi_{2}\right)(\%)$, one can calculate the corresponding BTDF values through Equation (1) (M. Andersen et al., 2003):

$$
\operatorname{BTDF}\left(\theta_{1}, \phi_{1}, \theta_{2}, \phi_{2}\right)=\frac{\Phi_{2_{\text {norm }}}}{\Delta \theta_{2}^{\mathrm{rad}} \cdot \Delta \phi_{2}^{\mathrm{rad}} \cdot \sin \theta_{2} \cos \theta_{2}}
$$

where the angular intervals $\Delta \theta_{2}$ and $\Delta \phi_{2}$ are here expressed in radians.

A ray-tracing plot example is displayed on Figure $7(\mathrm{~b})$ for the $0^{\circ}$ slats tilt configuration, for an incident direction $\left(\theta_{1}, \phi_{1}\right)=\left(12^{\circ}, 90^{\circ}\right)$. Only a few (about a thousand) of the 200,000 traced rays are shown on the plot, to get a still readable transmitted light distribution.

\section{Results comparison}

Once converted into the corresponding BTDF values through Equation (1), the simulated fluxes detected in each discretization sector data can be compared to the experimental BTDF values. Both measured and calculated BTDFs being assessed inside given angular areas around the associated couples $\left(\theta_{2}\right.$, $\left.\phi_{2}\right)$, they depend on the angular grid intervals $\Delta \theta_{2}$ and $\Delta \phi_{2}$. Indeed, they represent average values of $B T D F$ s inside these areas, and provide a continuous

- thus complete - investigation of the transmitted light distribution, unlike point-per-point data that provide $B T D F$ values along specific directions $\left(\theta_{2}\right.$, $\left.\phi_{2}\right)$.

In order to point out differences between real and virtual values with high accu- 
racy, two-dimensional plots for varying altitudes $\phi_{2}$ and along given azimuths $\theta_{2}$ are chosen instead of the more intuitive but less detailed 3D representations in spherical coordinates that are usually adopted for BTDF visualization (M. Andersen, 2002), shown for incidence $\left(24^{\circ}, 90^{\circ}\right)$ in Figure 8 . The results are shown on Figures 9 and 10.

For each analyzed situation, the relevant outgoing azimuthal planes (i.e. the angles $\phi_{2}$ for which the transmission is non-zero) were determined. Both measured and calculated BTDF data were reported along these outgoing planes as functions of altitude $\theta_{2}$ for the 15 selected incident directions. The azimuthal planes next to the most relevant ones were also checked (planes $\phi_{2_{m}} \pm \Delta \phi_{2}$ and $\phi_{2 m} \pm 2 \Delta \phi_{2}$, where $\phi_{2_{m}}$ is the azimuth angle for which the $B T D F$ reaches an extremum value) and generally revealed the same kinds of behaviours as the main plane (but with lower values), as shown on Figures 9(c), 9(f), 10(c), and 10(f). For conciseness, some section views show $\phi_{2}$ planes in pairs $\left(90^{\circ}\right.$ and $270^{\circ}, 75^{\circ}$ and $255^{\circ}$ ), the latter being then plotted with negative values for $\theta_{2}$ (Figures 9(a), 9(b), 9(c), 10(a), 10(b), 10(c) and 10(d)).

Globally speaking, the obtained results reveal that a remarkable agreement between real and virtual $B T D F$ values is achieved: the observed differences are almost always comprised within the error bars (their determination is explained in section 5) and remain below $8 \%$ on average, in relative terms. Even though the transmission features are generally sharp (high gradients increase the risk of having significant dissimilarities between two assessment methods), low discrepancies and an analogous qualitative light behaviour are observed for the experimental and computational methods, as well for the light transmitted directly (rays passing between the slats) as for the light that was redirected after reflection on the curved slats surfaces. 
The few situations where the observed discrepancies are higher (as e.g. in Figures 10(a), 10(d) and especially 9(d)) are generally associated with lower $B T D F$ values, where the sensitivity to the simulation conditions is greatly enhanced. If we consider the results of Figure 9(d) in particular, we can observe that they correspond to a light distribution where practically all the transmitted rays have undergone a reflection on the paint side of the slats (diffuse surface), which explains the low transmission value: a direct-hemispherical transmittance of $3 \%$ was found with both assessment methods. It will thus be considerably influenced by the model parameters, and more specifically by the paint coating specular component and reflection coefficient variations over the spectrum.

Figures 9 and 10 therefore make up a positive reciprocal validation, on one hand of the experimental set-up, and more specifically the adopted detection technique and the calibration and correction procedures, and on the other hand of the reliability and applicability of ray-tracing calculations for complex fenestration systems assessment.

\section{Error estimation}

A detailed analysis of the uncertainties due to the different CCD camera calibration stages, the additional corrections and data processing procedures as well as the spatial adjustment of the facility components was conducted in M. Andersen (2004); their relative impact on the final BTDF values was found to be equal to $10 \%$, which is expressed by the error bars associated with the "BTDF meas" curves in Figures 9 and 10. 
As far as the accuracy of the model results is concerned, it was estimated by adding the statistical error due to the number of traced rays to the sensitivity of the model to its exact parameters.

\subsection{Ray-tracing calculations accuracy}

The statistical error can be assessed using the theory of sampling: the probability of obtaining a result $P$ with less than a given error $\varsigma$ and with a determined confidence $C$ is related to the size of the sample (i.e. the number of rays $N_{R}$ ) by Equation (2):

$$
\varsigma=\sqrt{\frac{1}{N_{R} \cdot(1-C)} \cdot \frac{1-P}{P}}
$$

$P$ is the normalized emerging light flux reaching each averaging sector. Admitting a confidence level of $95 \%$ and tracing 200,000 rays per incident direction, we obtain a statistical error comprised between $4 \%$ and $0.5 \%$ : its exact value depends on the simulation model threshold (0.001 for the venetian blinds) and the emerging direction (the lower the value, the greater the error). An statistical error $\varsigma$ of $1 \%$ was thus considered.

The performance of the chosen software TracePro ${ }^{\circledR}$ was verified by comparing achieved BTDF data with results obtained with the validated Radiance programme for a laser cut panel.

For this purpose, it was modeled in both simulation programs with the same geometrical characteristics (P.J. Greenup et al., 2000) and using the same simplification hypotheses, in particular a null diffuse component on the parallel 
cuts. This hypothesis actually revealed a too strong approximation compared to reality, but allowed consistent results from one program to the other.

The chosen incidence direction was $\left(\theta_{1}, \phi_{1}\right)=\left(60^{\circ}, 90^{\circ}\right)$ and the corresponding BTDF was assessed according to adjacent hemisphere sectors of same intervals $\left(\Delta \theta_{2}, \Delta \phi_{2}\right)=\left(5^{\circ}, 5^{\circ}\right)$ for both models. Although the ray-tracing techniques were completely different (forward versus backwards ray-tracing), the obtained results agreed exceptionally well, only differing by $1 \%$ in relative terms: a strong confidence in the accuracy of the ray-tracing program was brought as a consequence.

\subsection{Model sensitivity study}

The relative error associated to the venetian blind's model was assessed by modifying slightly certain simulation parameters and examining how these changes affected the BTDF data, as the model can only approximately describe a physical - thus imperfect - venetian blind:

- small difference in the slats tilt $\left(3^{\circ}\right.$ anticlockwise when seen from $\phi_{i}=0^{\circ}$, each slat being hence shifted $0.6 \mathrm{~mm}$ to keep the interface at the same position);

- half a period slats position shift (37 mm further down);

- variation of the curvature radius $( \pm 1.8 \mathrm{~cm}$, the slats width being fixed);

- neutral mirror coating (constant reflectance of $83.7 \%$ over the spectrum, no diffuse component);

- neutral paint coating (constant reflectance of $28.6 \%$ over the spectrum, no specular component); this last parameter only affected the results signifi- 
cantly for the incident direction $\left(\theta_{1}, \phi_{1}\right)=\left(40^{\circ}, 270^{\circ}\right)$ shown on Figure $9(\mathrm{~d})$.

As mentioned in section 2.1, the edges of the venetian blind's slats were rounded in the simulation model, to be as close as possible to the physical prototype and to avoid aberrant ray paths. Nonetheless, sharp edges were proven to be of negligible influence on the $B T D F$ results.

A different simulation model was created for each parameter, the modification's impact being evaluated for two different incident directions: $\left(31^{\circ}, 30^{\circ}\right)$ and $\left(68^{\circ}, 45^{\circ}\right)$. Only the transmitted directions where BTDF data were greater than $5 \%$ of the curve maxima were considered for determining the resulting variations of $B T D F$ data.

In this study, the data corresponding to direct transmission peaks were separated from those corresponding to light transmitted after reflection on the mirrored side of the slats, so that errors could be associated individually to each of them. The $\left(40^{\circ}, 270^{\circ}\right)$ incidence was analyzed apart from the others, in order to assess the effect of the paint coating specifications when the diffuse transmission becomes significant compared to the other components.

The relative differences on $B T D F$ s generated by these modifications were gathered by parameter and averaged over the incident and transmitted directions. This led to relative inaccuracies of $14 \%, 5 \%, 4 \%$ and $0.3 \%$ for the regular peaks and $22 \%, 8 \%, 33 \%$ and $19 \%$ for the mirror reflected peaks, respectively associated to the slats tilt angle, position and curving radius and mirror coating's specifications. The paint coating parameter's effect was estimated to $58 \%$, which shows how sensitive low BTDFs were to even slight model differences. 
In the end, global errors of $16 \%, 45 \%$ and $58 \%$ were obtained respectively for regular, mirror and paint reflected transmission from calculating the Root Sum Square (RSS) of the relative individual errors, including those due to the limits of the model (M. Andersen et al., 2003) : threshold ( $1 \%$ error), number of emitted rays $(\sim 1 \%)$, discrete source spectrum $(\sim 2 \%)$.

Their large values show that the model's adequacy to provide a copy of the physical blind could rapidly be lowered with a slightly inappropriate choice of simulation parameters, or with flawed or irregularly manufactured slats. However, as shown by the close agreement between the "BTDF meas" and "BTDF $F_{\text {sim }}$ " curves for nearly all the studied situations in Figures 9 and 10, the blind's model can be considered as very satisfactory to conduct a reliable assessment of transmission performances on the basis of on ray-tracing simulations.

These relative errors are to be added to the statistical uncertainty associated to the number of traced rays. The resulting error bars are represented on Figures 9 to 10 and associated to "BTDF sim" curves.

\section{Conclusion}

The work presented in this paper is a further step in the appraisal of BTDF determination methods, based on comparisons between goniophotometric measurements and ray-tracing simulation results.

In M. Andersen et al. (2003), prismatic panels of standard refractive indices given by Fresnel laws were chosen to assess this roundabout approach in 
$B T D F$ validation. Here, more complex systems were chosen, both from the geometrical and the materials points of view: virtual copies of the slats were created taking the dimensions and spatial arrangement of the manufacturer's prototype into account, and the reflective properties of their coatings, mirror on the upper side, stone grey mat paint on the lower side, were determined experimentally with a spectrophotometer and implemented in the model.

The venetian blind model's transmission performances were then assessed with a virtual copy of the bi-directional goniophotometer developed at the LESOPB / EPFL: the light source spectrum and beam spread were imitated, and a virtual detection system reproducing the mobile triangular panel used as a projection screen for the transmitted light in the experimental device was modeled. Monte Carlo based ray-tracing calculations were then launched for two slats tilt configurations and 15 different incident directions. The comparisons between simulations and measurements showed remarkably close agreement, with discrepancies in average lower than $8 \%$, despite the very different assessment methods and the important number of parameters that had to be taken into consideration.

This work thus confirms the assertions established in M. Andersen et al. (2003), that supported the geometrical optics approach's ability to provide $B T D F$ results with a precision sufficient for glazing systems evaluations, and, conversely, that validated the experimental BTDF assessment technique. It even enhances them by showing that they remain valid with more complex systems, where critical components' optical properties have to be determined experimentally beforehand, and implemented in the ray-tracing tool. It is indeed shown that the accuracy reached in such intermediate characterizations is sufficient for final calculation results to be accurate and reliable, and strongly 
supports the concept of an assessment method combining both experimental and computational aspects.

\section{Acknowledgements}

This work was supported by the Assistant Secretary for Energy Efficiency and Renewable Energy, Office of Building Technology, State and Community Programs, Office of Building Research and Standards of the U.S. Department of Energy under Contract No. DE-AC03-76SF00098. Marilyne Andersen was supported by a joint funding from the Lawrence Berkeley National Laboratory and the Swiss National Science Foundation, fellowship 81EL-66225.

The authors wish to thank Lambda Research Corporation for having provided them with a license of TRACEPRO ${ }^{\circledR}$ to complete this research, as well as Dr. Laurent Michel for his kind help in determining the blind's geometric properties, and Christian Roecker and Pierre Loesch for their contribution in the goniophotometer's mechanical development.

\section{Nomenclature list}

BTDF Bidirectional Transmission Distribution Function $\left(\mathrm{Cd} \cdot \mathrm{m}^{-2} \cdot \mathrm{lux}^{-1}\right)$ or

$$
\left(\mathrm{sr}^{-1}\right)
$$

$\Phi_{2_{\text {norm }}}$ transmitted light flux normalized to the incoming flux(-)

$\theta_{1}, \phi_{1}$ polar co-ordinates of the incident light flux $\left(^{\circ}\right)$

$\theta_{2}, \phi_{2}$ polar co-ordinates of the emerging (either transmitted or reflected) light flux $\left(^{\circ}\right)$

$\Delta \theta_{2}, \Delta \phi_{2}$ angular intervals determining the BT(R)DF averaging grid $\left(^{\circ}\right)$ 
$\Delta \theta_{2}^{\mathrm{rad}}, \Delta \phi_{2}^{\mathrm{rad}}$ angular intervals determining the BT(R)DF averaging grid (rad) $\phi_{2_{m}}$ azimuth angle for which a BT(R)DF reaches a local maximum $\left(^{\circ}\right)$

$R_{\text {slat }}$ curvature radius of venetian blind slats $(\mathrm{mm})$

$\xi$ thickness of venetian blind slats ( $\mathrm{mm})$

$l_{\text {slat }}$ width of venetian blind slats $(\mathrm{mm})$

$e_{\text {slat }}$ curvature amplitude of venetian blind slats $(\mathrm{mm})$

$\varsigma$ statistical error on ray-tracing calculations induced by the number of traced rays $(-)$

\section{References}

Andersen, M., Michel, L., Roecker, C., Scartezzini, J.-L., 2001. Experimental assessment of bi-directional transmission distribution functions using digital imaging techniques. Energy and Buildings 33 (5), 417-431.

Andersen, M., 2002. Light distribution through advanced fenestration systems. Building Research and Information 30 (4), 264-281.

Andersen, M., Rubin, M.D., Scartezzini, J.-L., 2003. Comparison between raytracing simulations and bi-directional transmission measurements on prismatic glazing. Solar Energy 74 (2), 157-173.

Andersen, M., 2004. Innovative bidirectional video-goniophotometer for advanced fenestration systems. PhD thesis, EPFL, Lausanne.

Apian-Bennewitz, P., 1995. Messung und Modellierung von lichtstreuenden Materialien zur Computer-Simulation von Tageslichtbeleuchtung. PhD thesis, Albert-Ludwigs-Universität, Freiburg.

Breitenbach, J., Lart, S., Längle, I., Rosenfeld, J.L.J, 2001. Optical and thermal performance of glazing with integral venetian blinds. Energy and Buildings 33 (5), 433-442. 
Campbell, N.S., 1998. A Monte Carlo approach to thermal radiation distribution in the built environment. PhD. thesis, University of Nottingham, Nottingham.

CIE, 1932. Commission Internationale de l'Eclairage Proceedings, 1931. Cambridge University Press, Cambridge.

Compagnon, R., 1994. Simulations numériques de systèmes d'éclairage naturel à pénétration latérale (Numerical simulations of daylighting systems for sidelighting). PhD. thesis, Ecole Polytechnique Fédérale de Lausanne, Lausanne. Greenup, P.J., Edmonds, I.R., Compagnon, R., 2000. RADIANCE algorithm to simulate laser-cut panel light redirecting elements. Lighting Research and Technology 32 (2), 49-54.

Klems, J.H., Warner, J.L., Kelley, G.O., 1997. A comparison between calculated and measured SHGC for complex glazing systems. In: Proceedings of ASHRAE Transactions 102(1), Feb. 17-21 (1996), Atlanta, pp. 931-939.

Kuhn, T.E., Bühler, C., Platzer, W.J., 2001. Evaluation of overheating protection with sun-shading systems. Solar Energy 69 (Suppl. 6), 59-74.

McCluney, R., Sung, J., 1999. Simulation of Venetian Blind Optical Properties with Monte Carlo Ray Tracing. Technical Report, Florida Solar Energy Center, Cocoa, FL.

Papamichael, K.M., Klems, J., Selkowitz, S., 1988. Determination and Application of Bidirectional Solar-Optical Properties of Fenestration Materials. Technical Report LBL-25124, Lawrence Berkeley National Laboratory, Berkeley.

Reinhart, C.F., Walkenhorst, O., 2001. Validation of dynamic RADIANCEbased daylight simulations for a test office with external blinds. Energy and Buildings 33 (7), 683-697.

Rosenfeld, J.L.J., 1996. On the calculation of the total solar energy transmit- 
tance of complex glazings. In: Proceedings of the 8th International Meeting on Transparent Insulation, Freiburg, Germany. 


\section{List of Figures}

1 Venetian blind sample presenting curved slats with mirror and diffuse stone grey coatings on their upper and lower faces respectively.

2 Geometric properties of individual venetian blind slat

3 Modeling of the venetian blind's geometry.

4 Total reflectance, measured every $5 \mathrm{~nm}$, for both mirror and beige mat paint coatings of the curved venetian blinds slats manufactured by Baumann-Hüppe AG

$5 \quad B T D F$ assessment principle for the LESO-PB bidirectional video-goniophotometer.

6 Bidirectional Transmission Distribution Function and associated polar coordinates.

$7 \quad$ Goniophotometer simulation model for assessing BTDFs with ray-tracing calculations

8 BTDF (photometric solids) for the unperforated mirror blind, incidence $\left(\theta_{1}, \phi_{1}\right)=\left(24^{\circ}, 90^{\circ}\right)$.

$9 \quad B T D F\left(\mathrm{sr}^{-1}\right)$ vs. $\theta_{2}\left(^{\circ}\right)$ along $\phi_{2}$ planes: comparison of measurements $\left(B T D F_{\text {meas }}\right)$ and calculations $\left(B T D F_{\text {sim }}\right)$ for the $0^{\circ}$ slats tilt configuration.

$10 B T D F\left(\mathrm{sr}^{-1}\right)$ vs. $\theta_{2}\left(^{\circ}\right)$ along $\phi_{2}$ planes: comparison of measurements $\left(B T D F_{\text {meas }}\right)$ and calculations $\left(B T D F_{\text {sim }}\right)$ for the $45^{\circ}$ slats tilt configuration. 


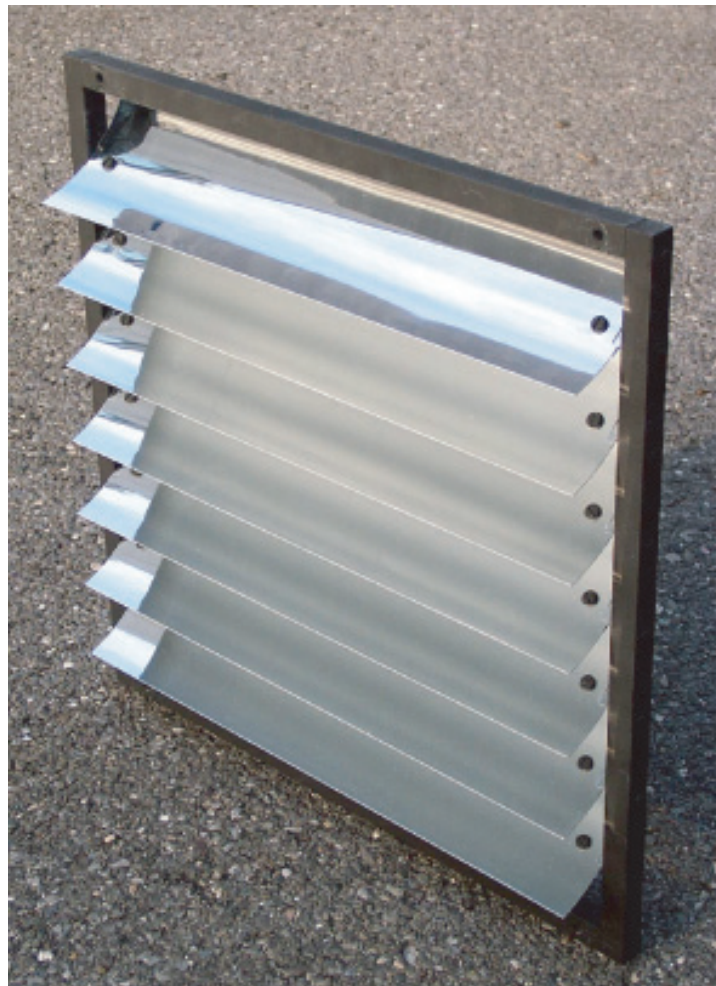

(a) Full sample

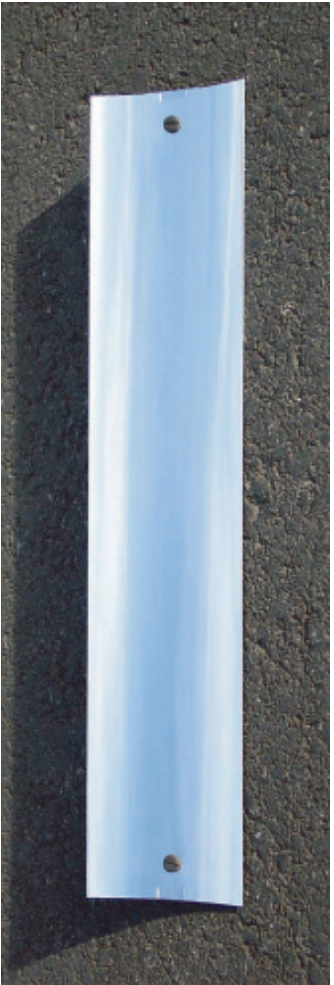

(b) Mirror side

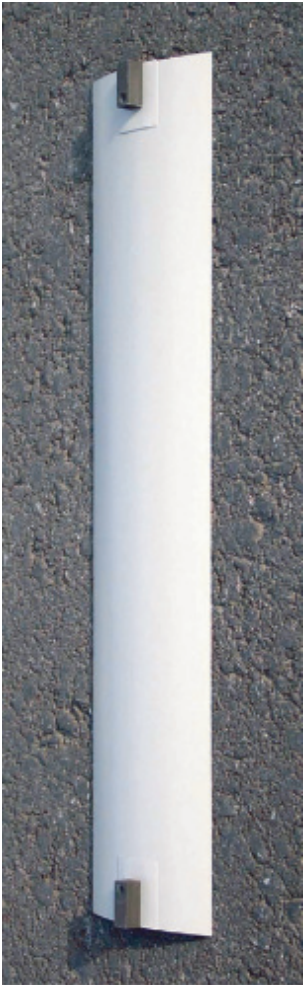

(c) Paint side

Fig. 1. Venetian blind sample presenting curved slats with mirror and diffuse stone grey coatings on their upper and lower faces respectively. 


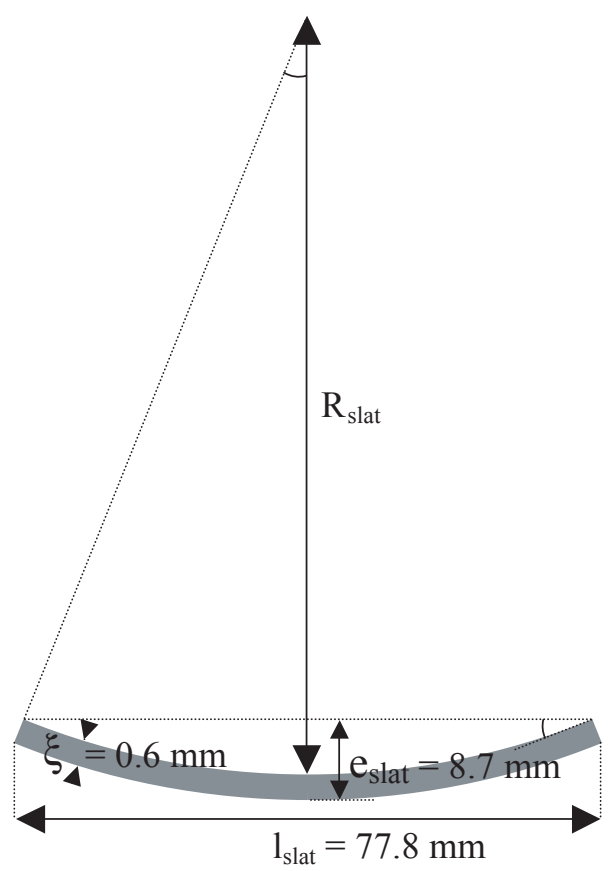

Fig. 2. Geometric properties of individual venetian blind slat 


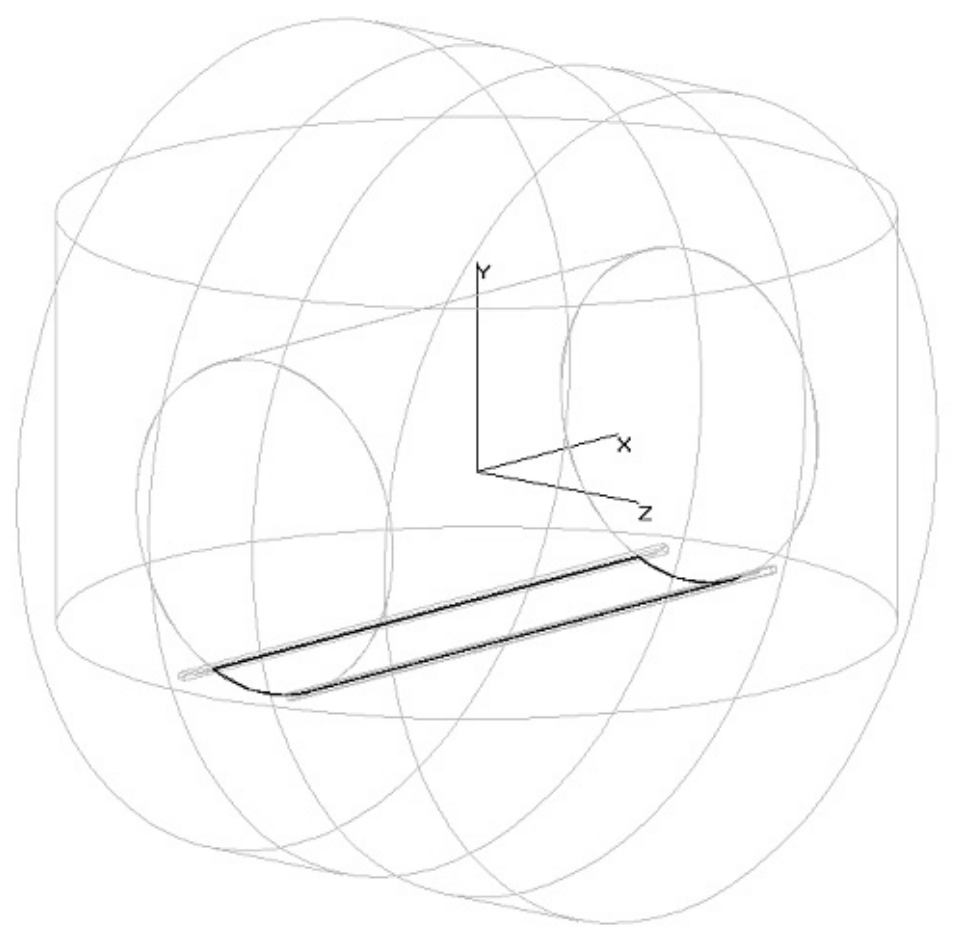

(a) Modeling of slat element
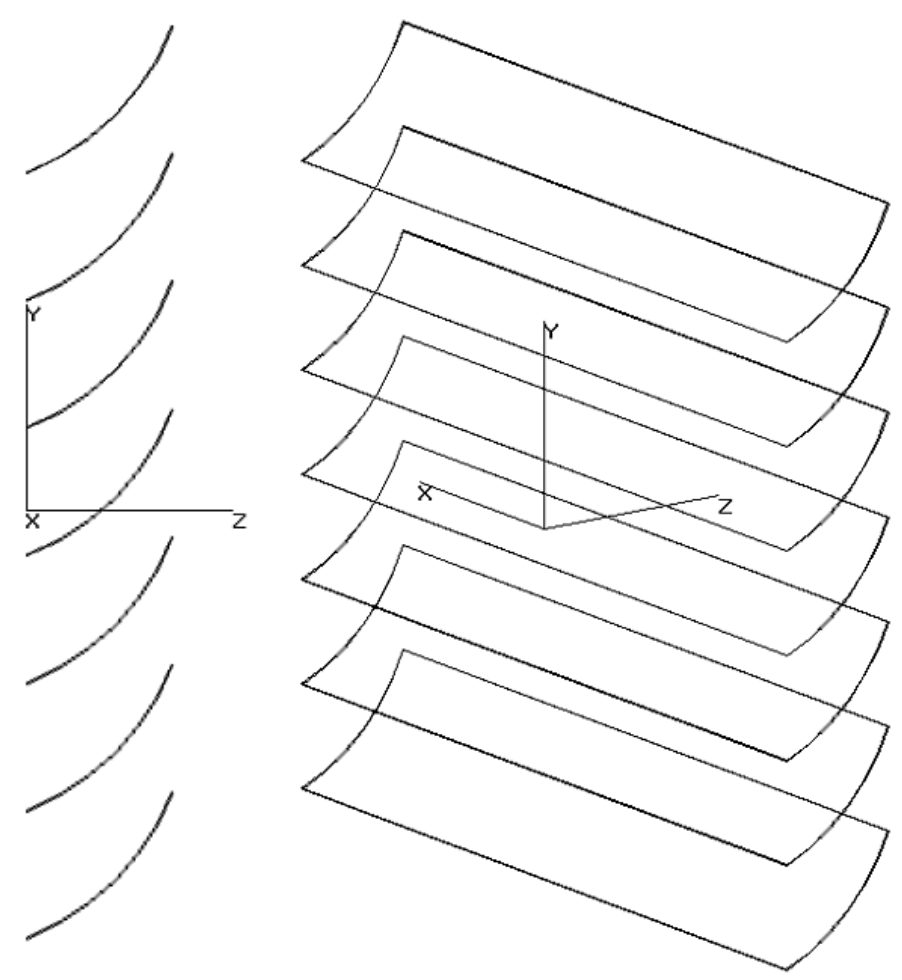

(b) $45^{\circ}$ tilt slats configuration

Fig. 3. Modeling of the venetian blind's geometry. 


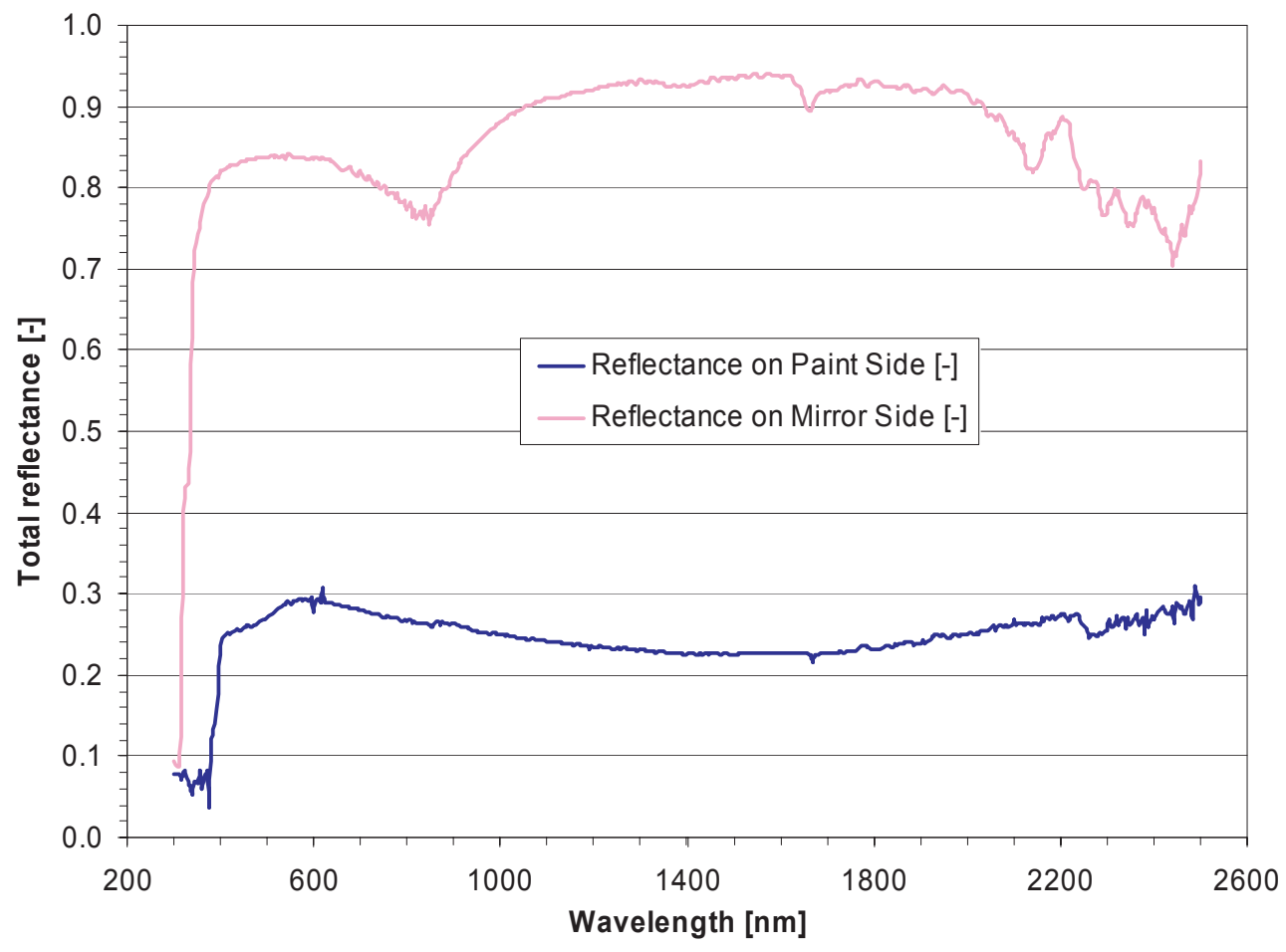

Fig. 4. Total reflectance, measured every $5 \mathrm{~nm}$, for both mirror and beige mat paint coatings of the curved venetian blinds slats manufactured by Baumann-Hüppe AG 


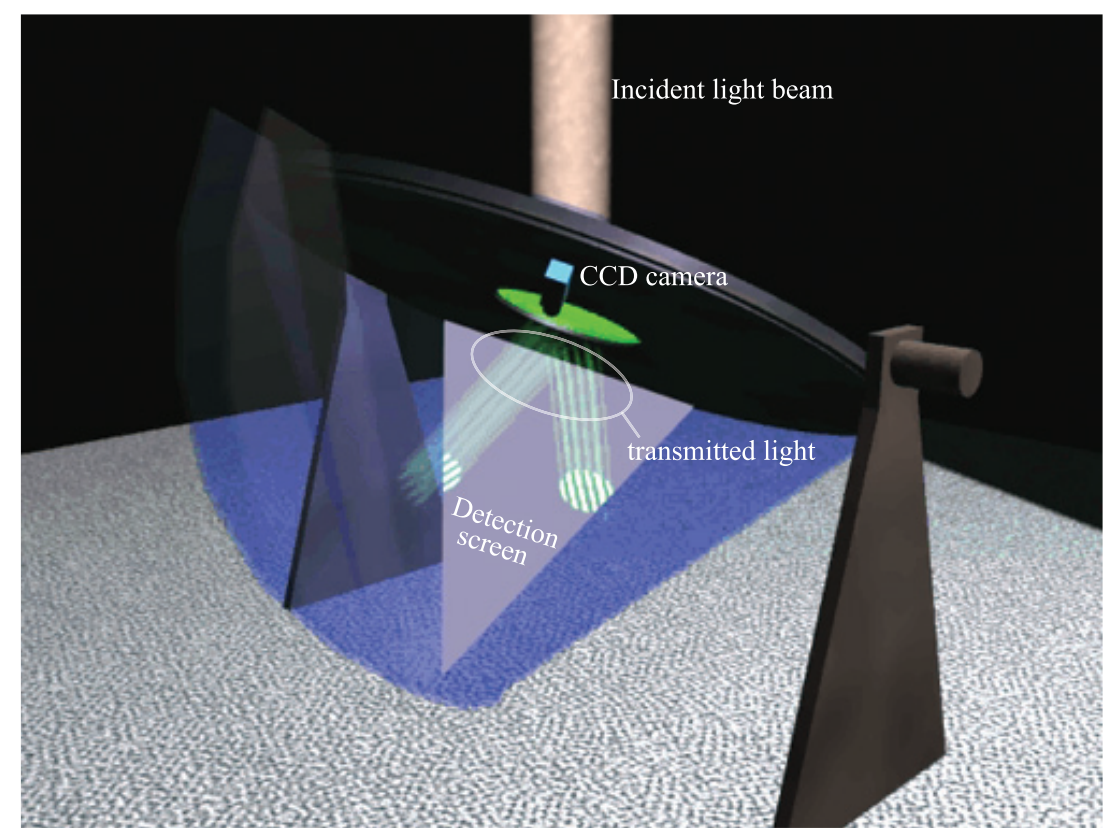

(a) Transmitted light flux detection

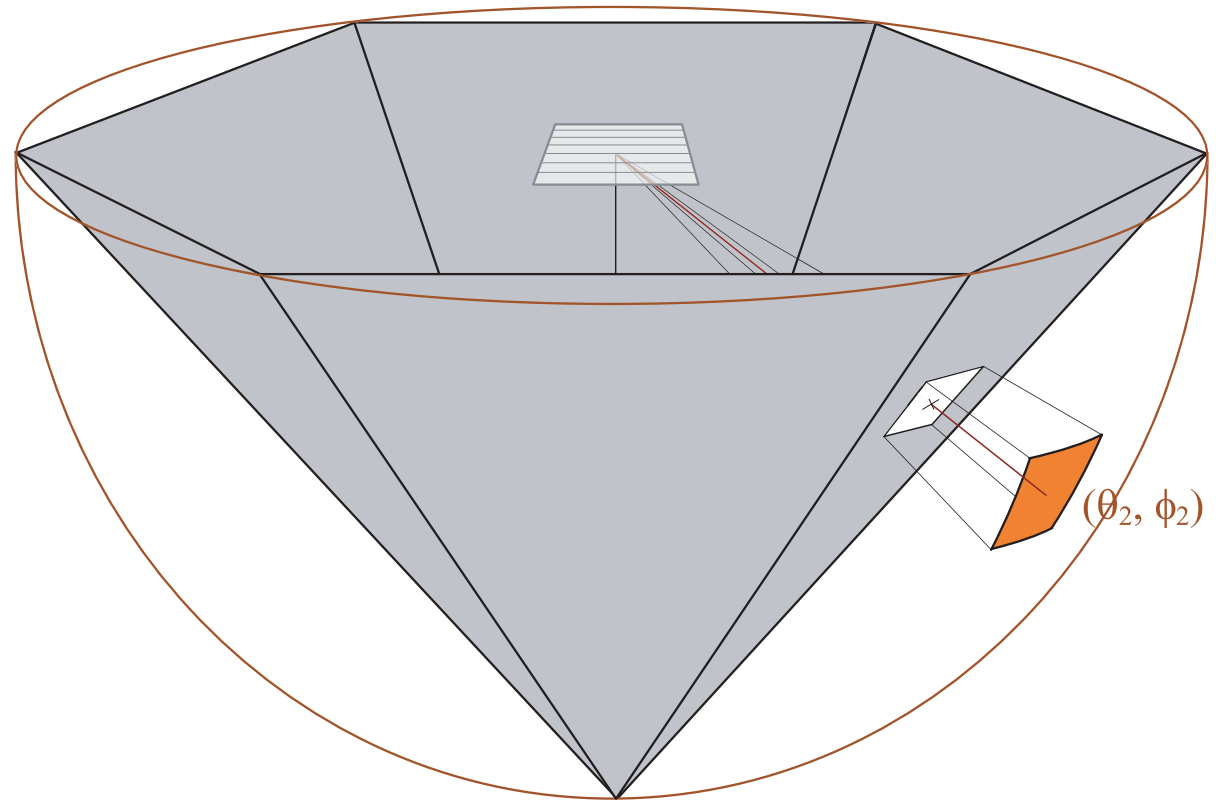

(b) Subdivision of hemisphere into averaging sectors

Fig. 5. BTDF assessment principle for the LESO-PB bidirectional video-goniophotometer. 


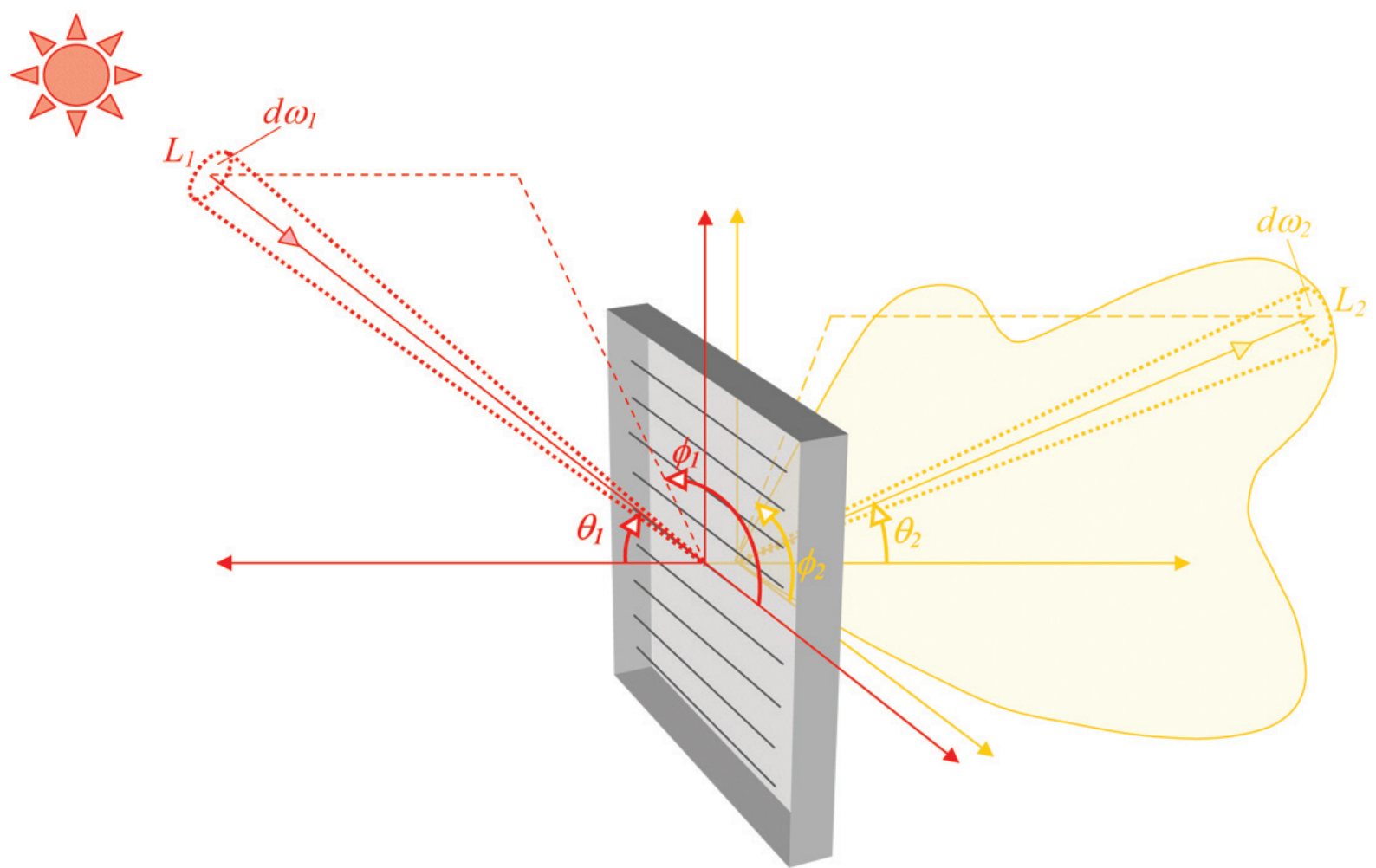

Fig. 6. Bidirectional Transmission Distribution Function and associated polar coordinates. 


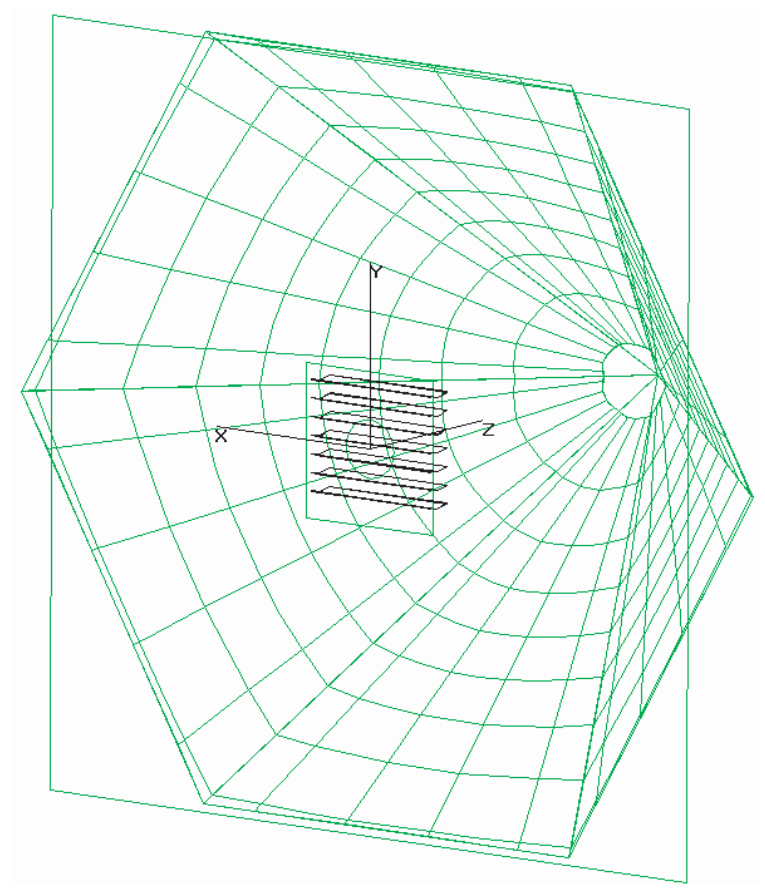

(a) Simulation model with six detection screens split into angular sectors $\left(\Delta \theta_{2}, \Delta \phi_{2}\right)=\left(10^{\circ}, 15^{\circ}\right)$

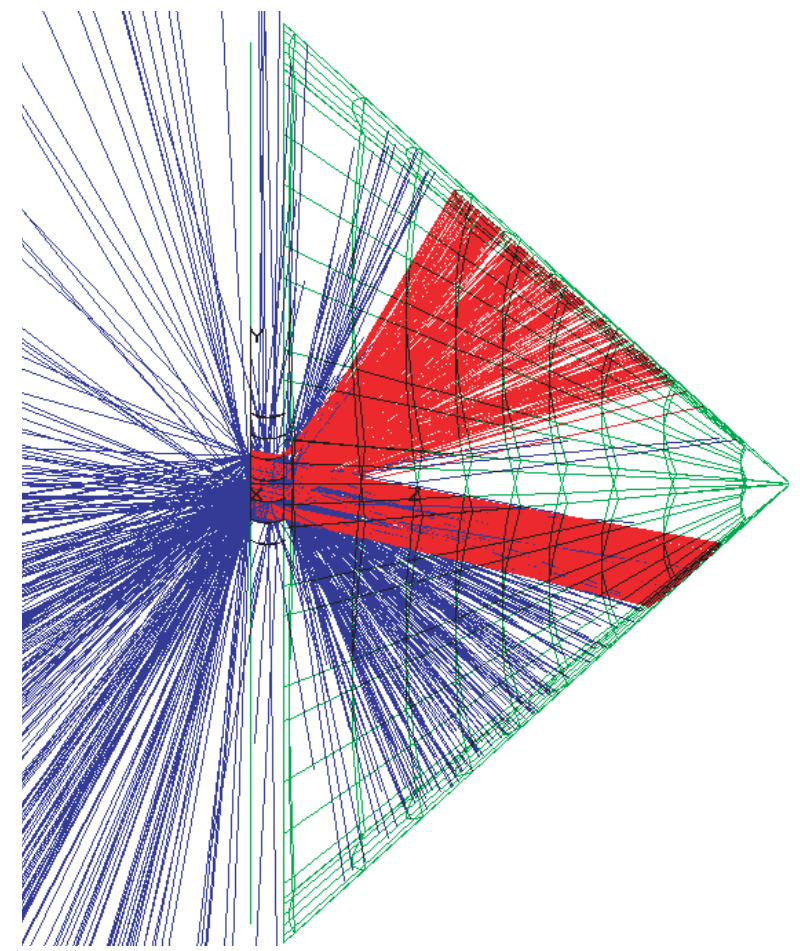

(b) Ray-tracing plot for incidence $\left(12^{\circ}, 90^{\circ}\right)$ (reflected part towards the left)

Fig. 7. Goniophotometer simulation model for assessing BTDFs with ray-tracing calculations 


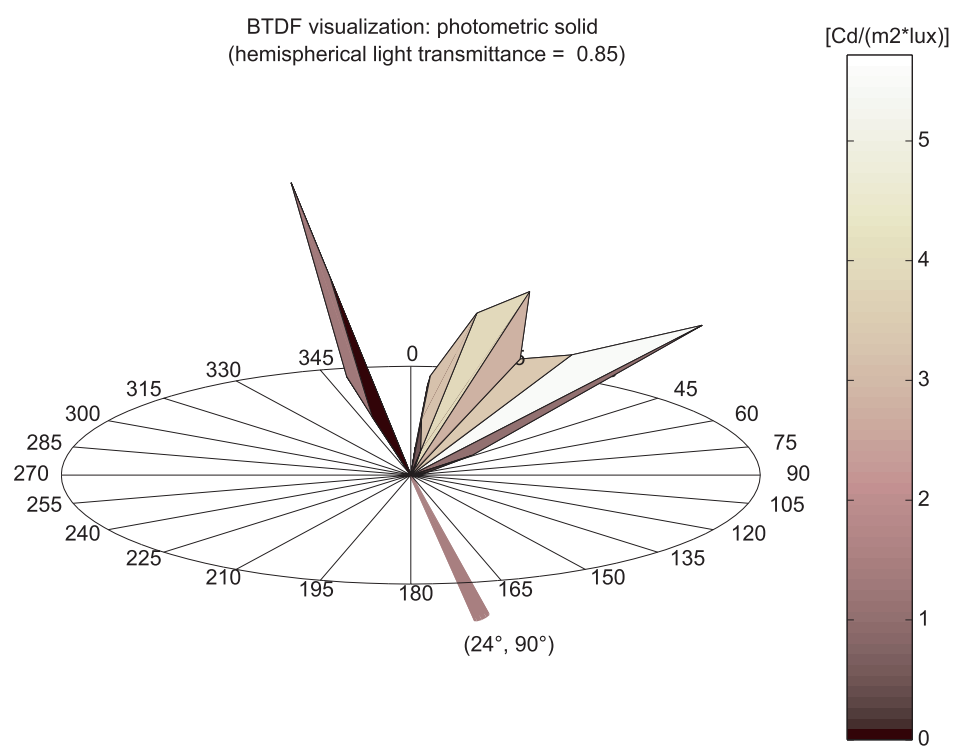

(a) BTDF for full slats, $0^{\circ}$ tilt

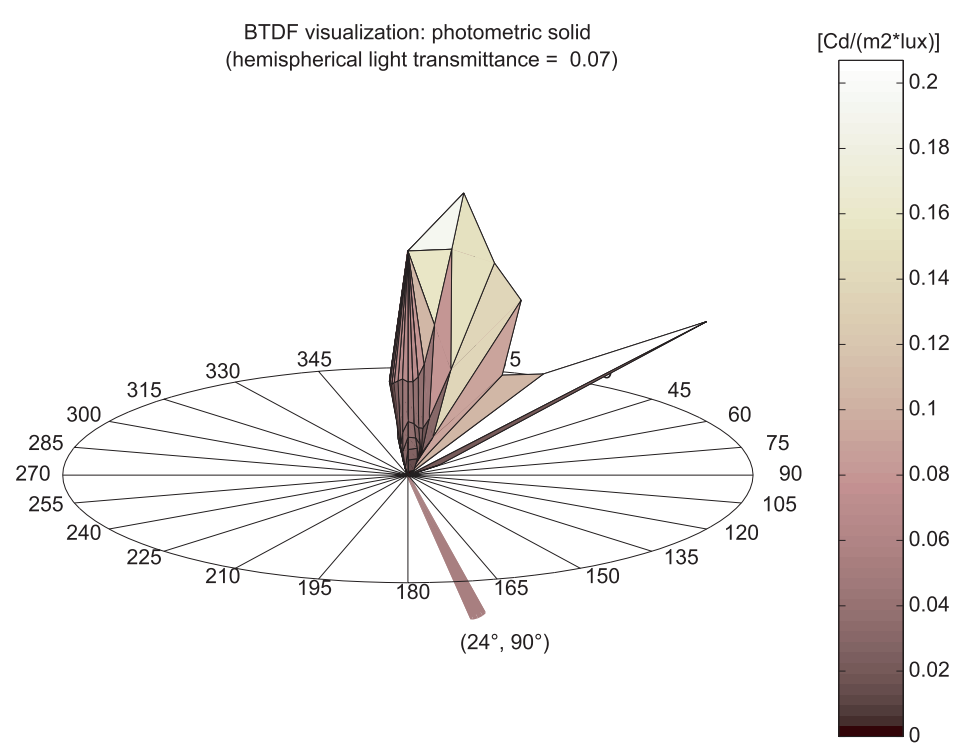

(b) BTDF for full slats, $45^{\circ}$ tilt

Fig. 8. BTDF (photometric solids) for the unperforated mirror blind, incidence $\left(\theta_{1}, \phi_{1}\right)=\left(24^{\circ}, 90^{\circ}\right)$. 


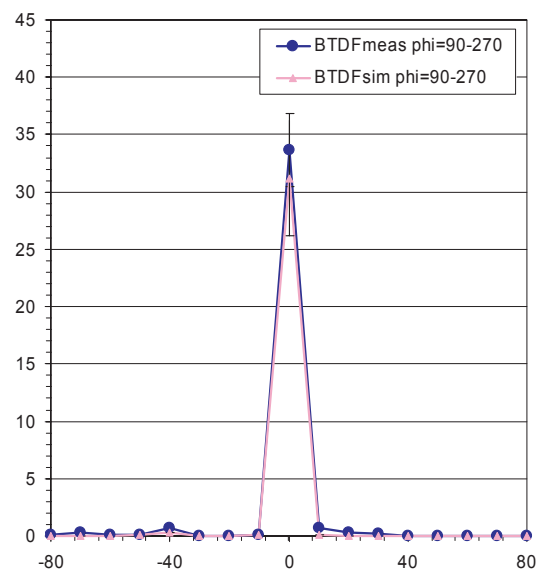

(a) Incidence $\left(\theta_{1}, \phi_{1}\right)=\left(0^{\circ}\right.$, $\left.0^{\circ}\right)$ : Direct transmission peak

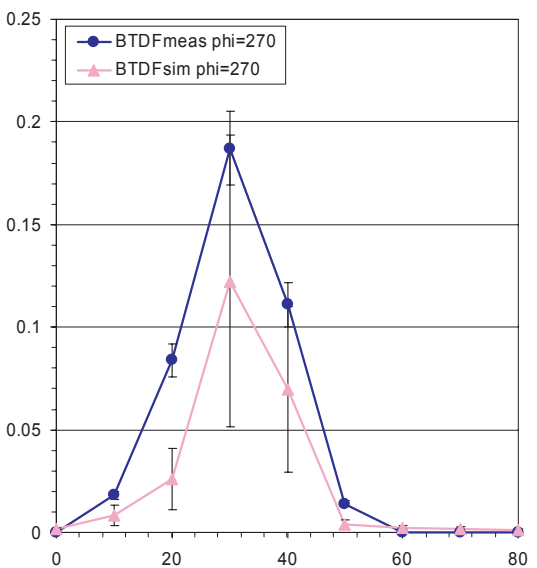

(d) Incidence $\left(\theta_{1}, \phi_{1}\right)=\left(40^{\circ}\right.$, $\left.270^{\circ}\right)$ : Light transmitted after reflection on the slats paint side only

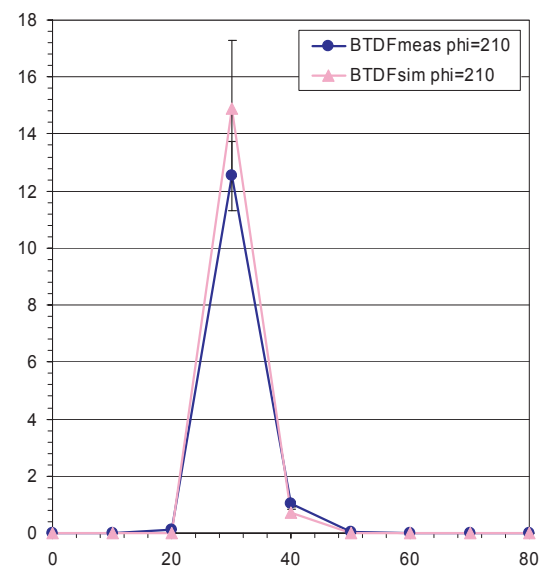

(g) Incidence $\left(\theta_{1}, \phi_{1}\right)=$ $\left(31^{\circ}, 30^{\circ}\right)$ : Direct transmission peak

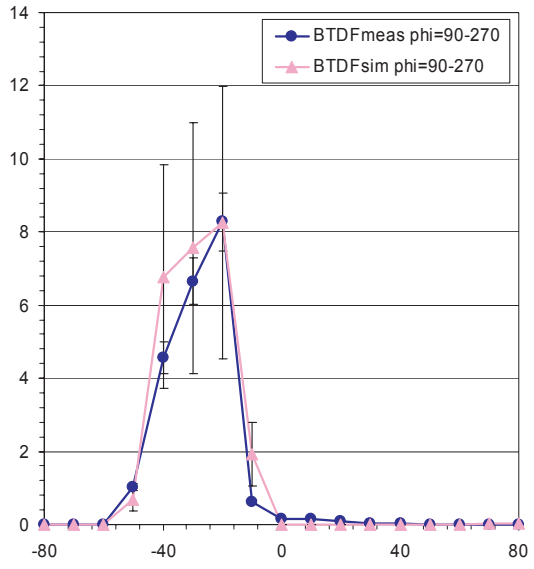

(b) Incidence $\left(\theta_{1}, \phi_{1}\right)=\left(60^{\circ}\right.$, $\left.90^{\circ}\right)$ : Main section view for mirror reflected transmission

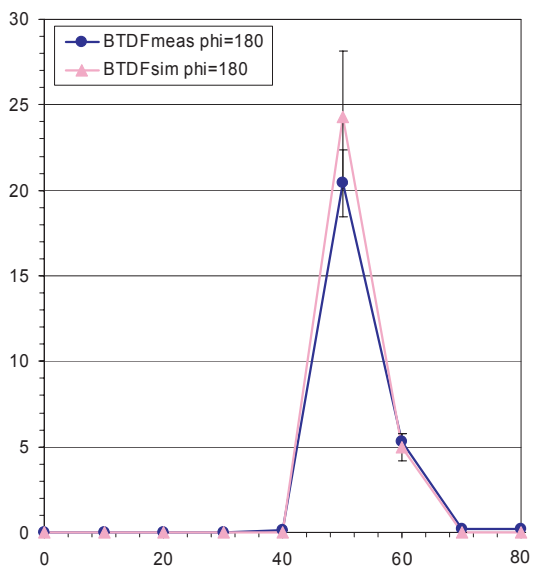

(e) Incidence $\left(\theta_{1}, \phi_{1}\right)=\left(53^{\circ}\right.$, $\left.1^{\circ}\right)$ : Direct transmission peak

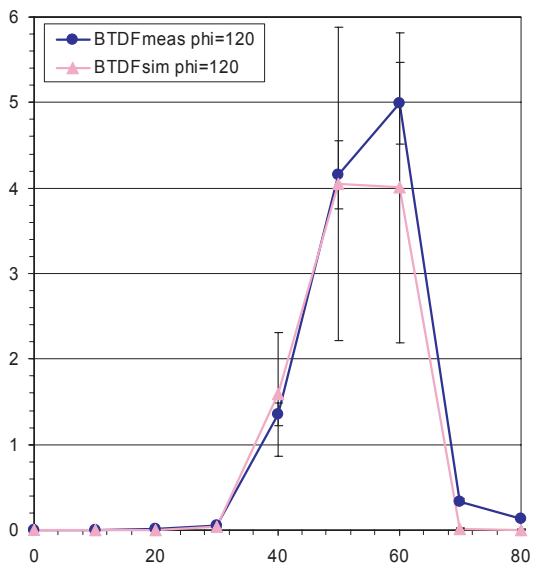

(h) Incidence $\left(\theta_{1}, \phi_{1}\right)=\left(31^{\circ}\right.$, $\left.30^{\circ}\right)$ : Light transmission after reflection on the slats mirror side

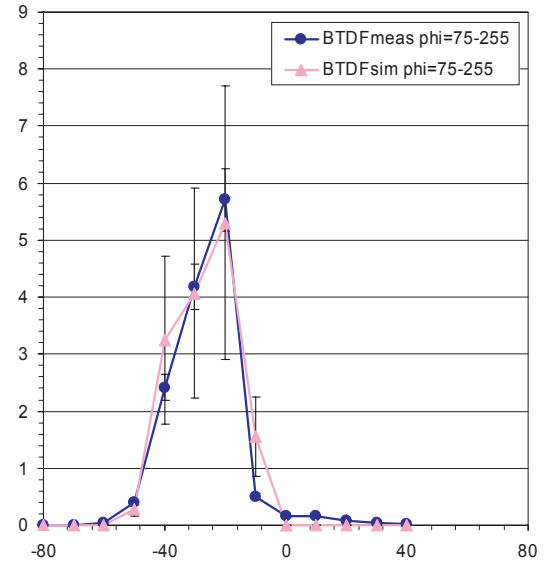

(c) Incidence $\left(\theta_{1}, \phi_{1}\right)=\left(60^{\circ}\right.$, $\left.90^{\circ}\right)$ : Adjacent section view for mirror reflected transmission

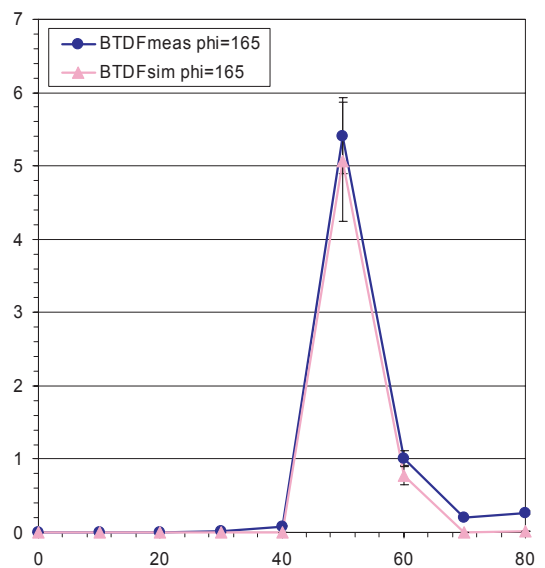

(f) Incidence $\left(\theta_{1}, \phi_{1}\right)=\left(53^{\circ}\right.$, $\left.1^{\circ}\right)$ : Adjacent section view for direct peak

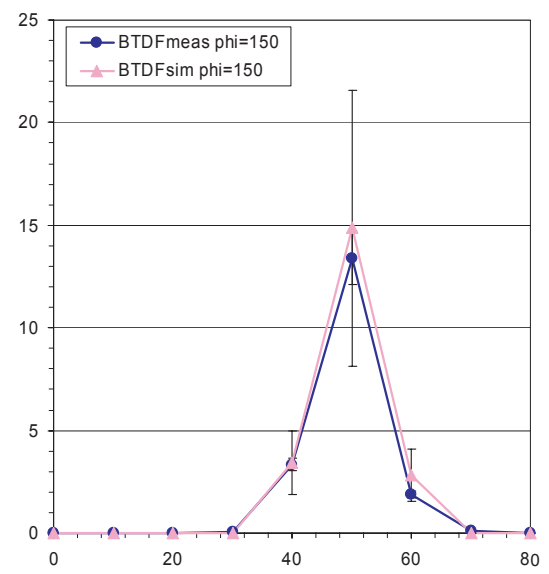

(i) Incidence $\left(\theta_{1}, \phi_{1}\right)=\left(68^{\circ}\right.$, $\left.45^{\circ}\right)$ : Mirror reflected peak

Fig. 9. $B T D F\left(\mathrm{sr}^{-1}\right)$ vs. $\theta_{2}\left(^{\circ}\right)$ along $\phi_{2}$ planes: comparison of measurements $\left(B T D F_{\text {meas }}\right)$ and calculations $\left(B T D F_{\text {sim }}\right)$ for the $0^{\circ}$ slats tilt configuration. 


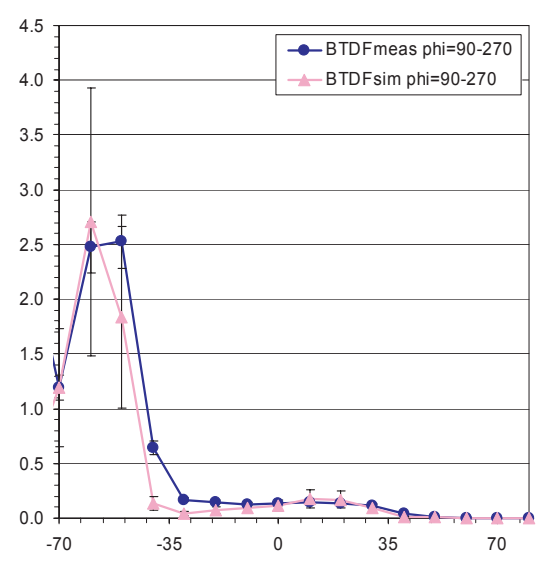

(a) Incidence $\left(\theta_{1}, \phi_{1}\right)=\left(0^{\circ}\right.$, $\left.0^{\circ}\right)$ : Light transmission after reflection on the slats mirror side

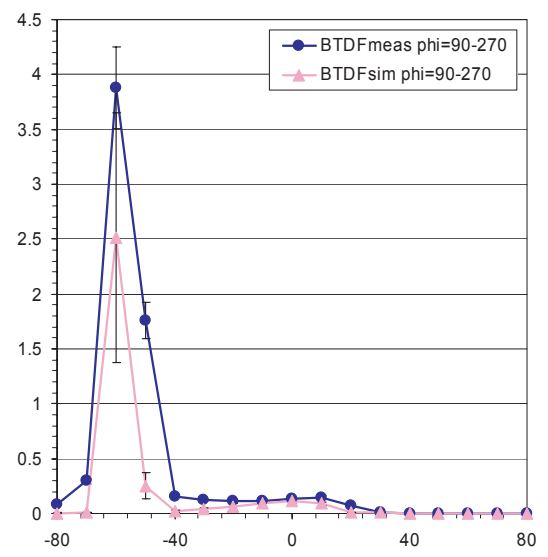

(d) Incidence $\left(\theta_{1}, \phi_{1}\right)=\left(12^{\circ}\right.$, $\left.90^{\circ}\right)$ : Direct and mirror reflected transmission

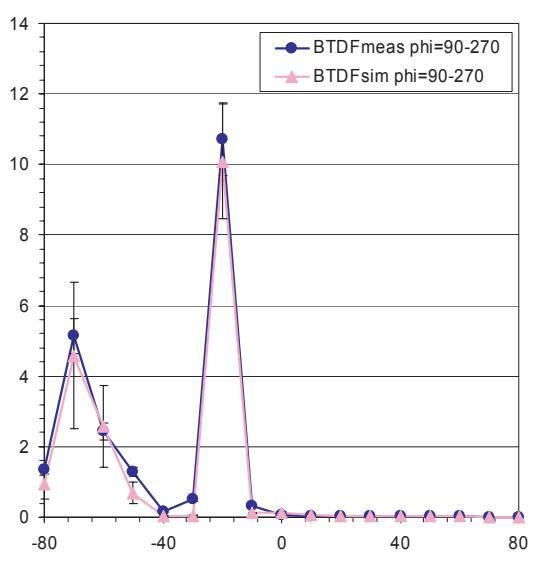

(b) Incidence $\left(\theta_{1}, \phi_{1}\right)=\left(20^{\circ}\right.$, $\left.270^{\circ}\right)$ : Main section view for direct and mirror reflected transmission

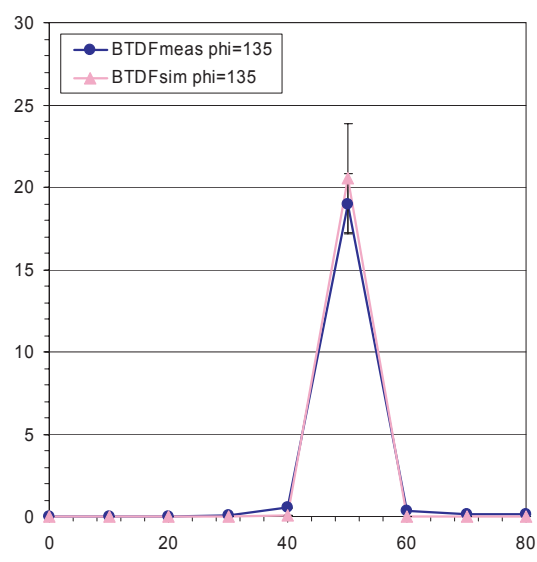

(e) Incidence $\left(\theta_{1}, \phi_{1}\right)=\left(50^{\circ}\right.$, $\left.315^{\circ}\right)$ : Main section view for direct transmission

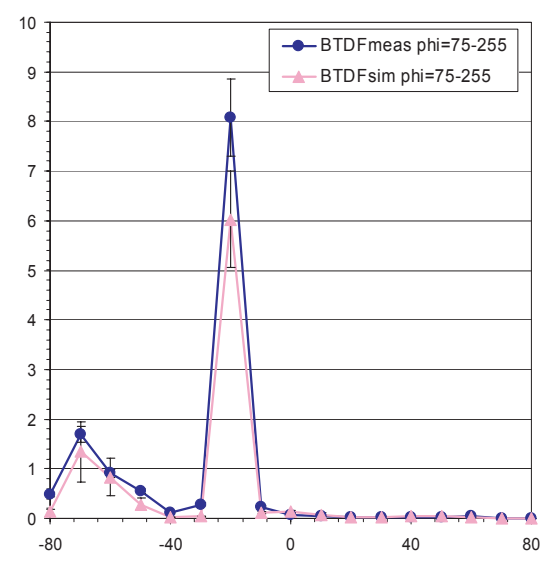

(c) Incidence $\left(\theta_{1}, \phi_{1}\right)=\left(20^{\circ}\right.$, $\left.270^{\circ}\right)$ : Adjacent section view for direct and mirror reflected transmission

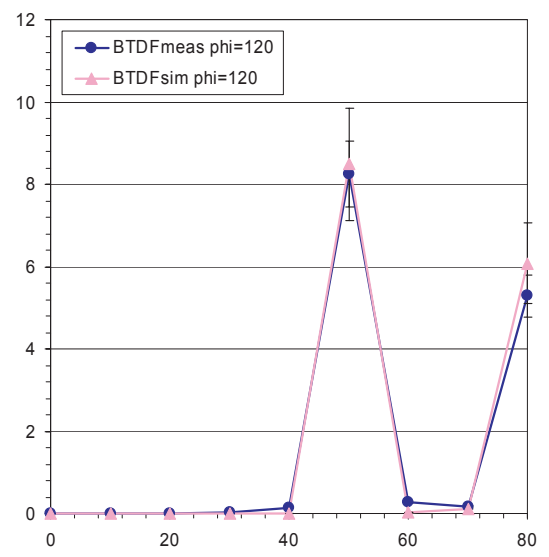

(f) Incidence $\left(\theta_{1}, \phi_{1}\right)=\left(50^{\circ}\right.$, $\left.315^{\circ}\right)$ : Adjacent section view for direct transmission

Fig. 10. $B T D F\left(\mathrm{sr}^{-1}\right)$ vs. $\theta_{2}\left(^{\circ}\right)$ along $\phi_{2}$ planes: comparison of measurements $\left(B T D F_{\text {meas }}\right)$ and calculations $\left(B T D F_{\text {sim }}\right)$ for the $45^{\circ}$ slats tilt configuration. 